\title{
Rhythmic Gymnastics of the Early Childhood
}

\author{
Endang Murti Sulistyowati \\ Master Program in Sport Science \\ Universitas Negeri Yogyakarta \\ Yogyakarta, Indonesia \\ endangmurti.2017@student.uny.ac.id
}

\author{
Endang Rini Sukamti \\ Faculty of Sport Sciences \\ Universitas Negeri Yogyakarta \\ Yogyakarta, Indonesia \\ endang_fik@uny.ac.id
}

\begin{abstract}
- the aim of this scientific study is to have a better understanding of the Rhaythmic Gymnastics and its effect on females' students that started since their early childhood and to create more insight about the sports to the trainers. Rhytahmic Gymnastics has its various characteristics at every stage. The concept of Rhythmic Gymnastics for early childhood made use of play patterns. Rhythmic Gymnastics early childhood involves participating in gymnastics without any sport tools (Free Hand) and then to the phase that has to do with sport tools such as bell, rope, hoop, clubs and ribbons. The training of Rhythmic Gymnastic is for children between the ages of 46years old, 7-8 years old, 9-11 years old; the golden age is achieved in their early ages. There are three basic types of movements Locomotor, Non-Locomotor and manipulative. The impacts of these sports on early childhood was discovered in this study.
\end{abstract}

Keywords—rhythmic gymnastics, early childhood

\section{INTRODUCTION}

Rhythmic gymnastics has been introduced in elementary schools and are taught during sports lesson hours. The essence of this is to help the trainers teach the dynamics of rhythmic gymnastics, the ability of studying the movements involved and the basic components of rhythmic gymnastic to the children. It also aids in the development of the child's motor skills such as running, throwing, walking etc. By programming the practice of motor skills, both routinely and repeatedly, aids in the perfection of motor skills. This stage occurs on the multilateral stage of the training pyramid ${ }^{[2]}$.

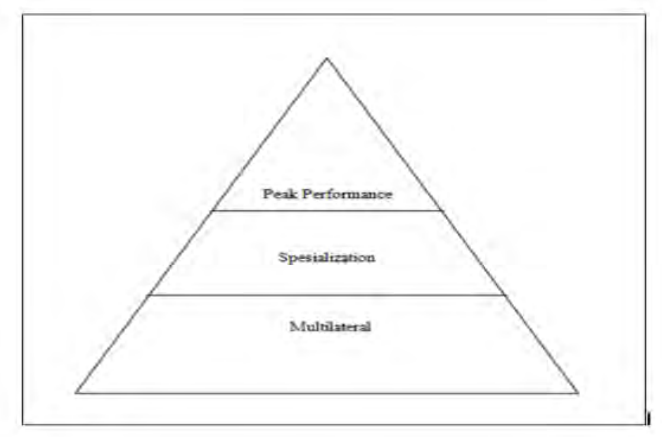

Fig. 1. Pyramid Training

Since gymnastics is introduced at early childhood, playful methods should be applied, and the trainer should be able to make the athletes happy and comfortable when they do the sports practices. Rhythmic gymnastics is unique because the movement is accompanied by music. Two aspects of rhythmic gymnastics are rhythmic perception and rhythmic execution. Rhythmic perception is there is harmony between the music and the movement body while rhythmic execution is the movement of the body according to the beats of the music. Rhythmic Gymnastics is not only related to the music or ballet but also to the dynamic motor movement. This gymnastics is also known as the special gymnastics because the participants are only females and this can be done individually or in groups. This gymnastics has several stages based on the age group of the participants. Every movement has to be harmonious with the breathing rules, the tension and the body movements. This helps improve the participants' stamina, the muscle strength, the controlling rhythm of the music and development of the athletes' creativity. The essence of rhythmic gymnastics is to improve the skills of the sports, to participate in competitions to enable the athletes to understand the techniques, and tactics, involved and to develop the right body posture [4-5]. The body postures ideal for rhythmic gymnastics are little, small, and slim body mass index. Rhythmic gymnastics requires flexibility. Basic gymnastics in early childhood cannot be separated from these three aspects locomotor, non- and manipulative. The locomotor deals with body movements such as walking, running, jumping, rolling and cycling. The non-locomotor deals with motionless activities that is activities that requires one to be at a point while moving only the joints such as throwing, catching, kicking, hitting, hanging, bouncing. Manipulative is the ability of combining certain objects with body movements. The tools used in rhythmic gymnastics are ball, rope, ribbon, hoop, and club while the movement is dependent on the ability of the athlete to combine the tools with the body movements [7].

The basic movement of rhythmic gymnastics are pivot, jump, balance, and acrobatics movements. The acrobatic movements are front rolling, back rolling, and wheeling. , the athletes should be taught to pass through the free hand stage, which is the gymnastics without tools. The length of the rope used in rhythmic gymnastics depends on the need. Both ends of the rope are held as high as the shoulders or ears, while the middle part of rope is stepped on by both feet (as can be seen in picture 2). The Hoop is either flat or round in shape; the length of the diameter for beginners is $70 \mathrm{cms}$ while for adult is $80-90 \mathrm{cms}$. The weight should not be more than 300 grams (as seen in picture 3). The Clubs weight 150 grams and the length is $40 \mathrm{cms}-50 \mathrm{cms}$ (as seen in picture 4). The Ribbon is usually made from satin cloth, and the length for beginners is $4 \mathrm{MS}$, while the length for adults is $6 \mathrm{~ms}$, the width is, $4-5 \mathrm{cms}$. The length of the stick is $50-60 \mathrm{~cm}$ (as seen in picture 5). The weight of the ball is 400 grams and the diameter is $18-21 \mathrm{cms}$ (picture 6) [8]. 


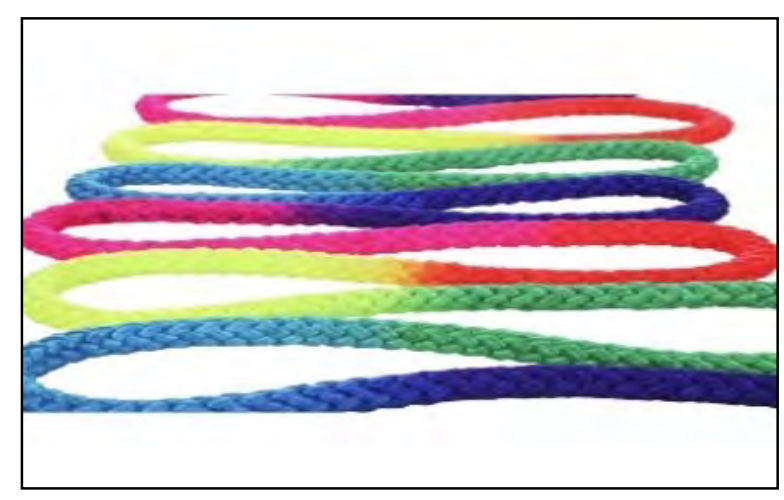

Fig. 2. Ropes

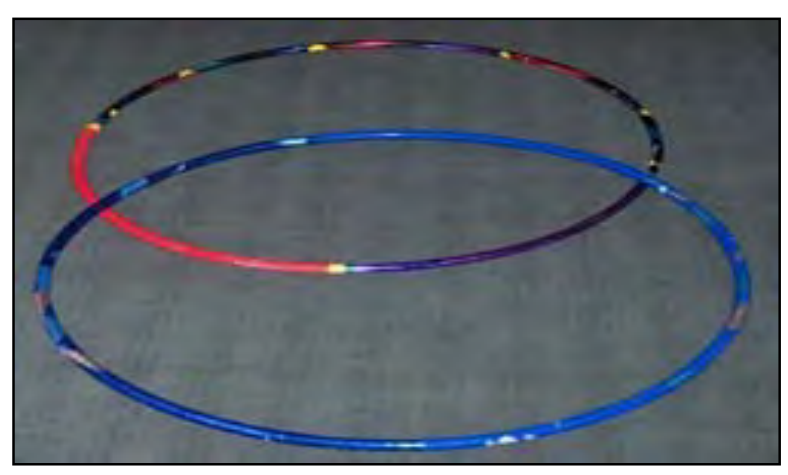

Fig. 3. Hoops

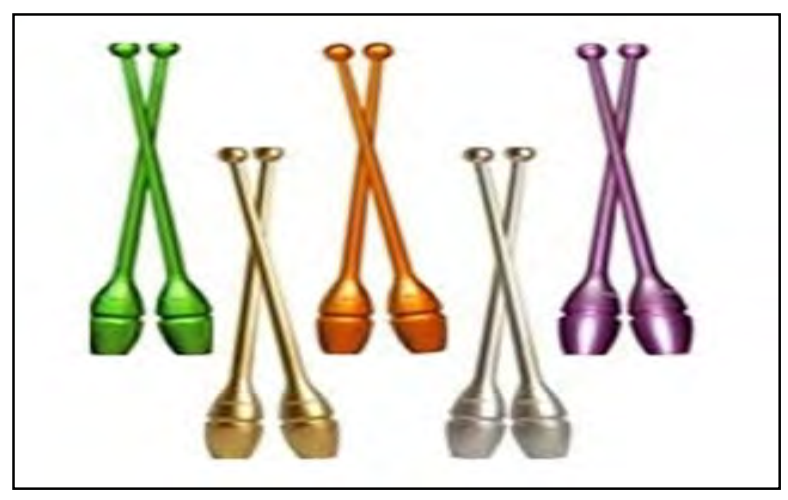

Fig. 4. Clubs

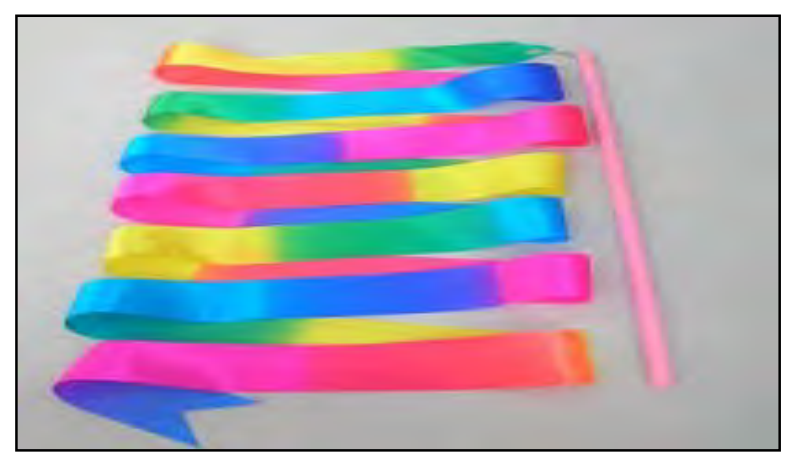

Fig. 5. Ribbons

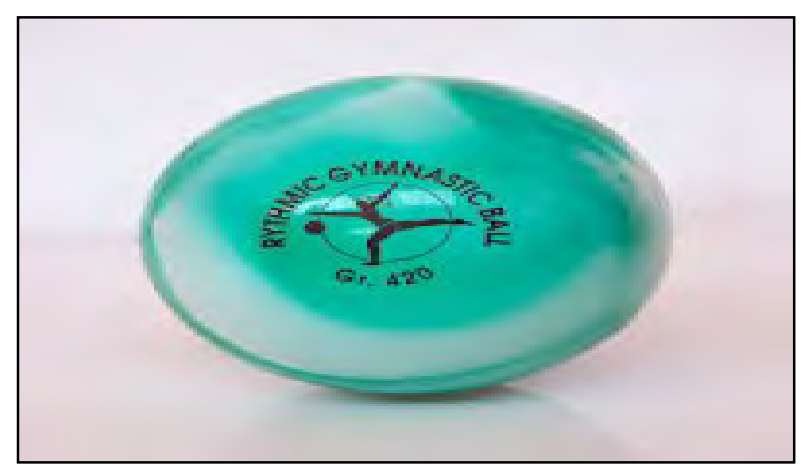

Fig. 6. Balls

The motor development in the children cannot be separated from the skills development. Generally, the children in elementary school are fond of doing physical exercises such as running, jumping, climbing, which involves moving their body parts. By playing, children can learn how to socialize, tolerate, become disciplined, respect and appreciating each other's' physical skills. Getting involved in physical activities can have a significant effect on children's development [10].

A child can be said to be active when he/she participates in activities such as running fast, which helps them to develop strong little muscles. They also start learning simple vocabularies; they learn how to interact with the teacher. They are very curious. They are not afraid of making mistakes. When children run, they rarely fall because they try to maintain their body balance. They are able to understand others when they speaking. Their thinking ability also increases rapidly [11].

Children between the ages of 7-8 years old, have a better understand of the skills and the rules of the games. They also start to develop motor skills such as skipping, running, and jumping. Children in this stage begin to learn about concentration, agility, coordination and other new movements. Their confidence level improves, and they learn more about independence and are definitely more curious. Their bones are still very soft and delicate; children between the ages of 9-11 years old are introduced to a variety of games including the more complex ones. Children within this age range can participate in group/team discussion. They understand the anatomy and strength of the males and females. The limb growth is stronger. They start to adapt to their surrounding environment. They explore their abilities. The emotional feeling starts to appear, and they start to learn how to control their emotions, which may be very difficult for them, but they are very optimistic. Children are more enthusiast and excited with new things [12].

\section{METHOD}

The method used for this study is the preliminary study design. The preliminary study was based on the interview and observations on the variables of rhythmic gymnastics in early childhood.

This study was held at four districts and one city of the Special Region of Yogyakarta from March to May 2018. The researcher using the initials of the children such as their ages and schools noted the result of the observations and interviews. This method saw two aspects, the trainers and the athletes. The data collected corresponded with the 
observations made by the researcher according to the preliminary study variables.

The number of trainers in the Special Region of Yogyakarta is five while the number of athletes in the Special Region of Yogyakarta is 35.According to the observations made by the researcher, the rhythmic gymnastics trainers were very few, every district of the Special Region of Yogyakarta had only one trainer and the athletes were also few. The gymnastics participants were only females and they started from early childhood 4 to 6 years old to be precise because they were more flexible at such tender ages. They practiced three times in a week but whenever they had any competition, they practiced for four or five times in a week. Because the basis of rhythmic gymnastics is flexibility, the practice of flexibility must be done routinely and sustainably until the appropriate movement is achieved.

The first movement of rhythmic gymnastics is like that of an athlete doing right, left or center splits by stretching both feet in the left and right directions making a straight line with the body properly aligned to the floor. This position indicates that the athlete has good flexibility as seen in figure 7 . The bridges posture is done by positioning the body in a recumbent manner on the floor, with both feet bent near the bottom and both hands bent near the ears then the body is gradual lifted up so that it forms the letter U. Flexibility can be measured by stretching the hands to reach the feet so that the body forms the letter $\mathrm{O}$ (as seen on figure 8). This position can be done by taking a sitting position with the feet positioned in line with the body at the same time straightening the body. There is a tool called sit and reach which can be used to take measurement of this posture. The Body is bent in an upfront position while the hands are placed in front touching the instrument so that the flexibility can be measured (as seen on figure 9).

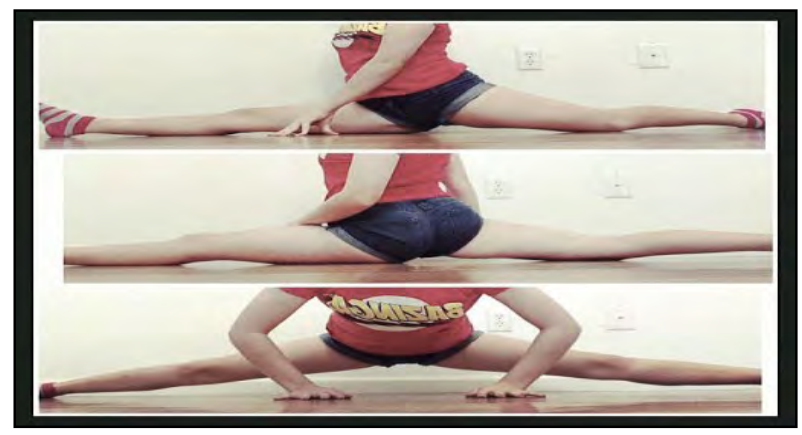

Fig. 7. Right split, left split, center split

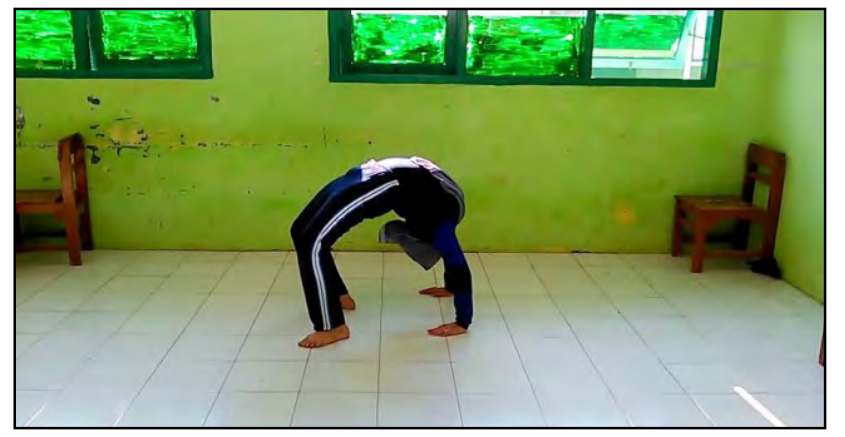

Fig. 8. The bridges posture

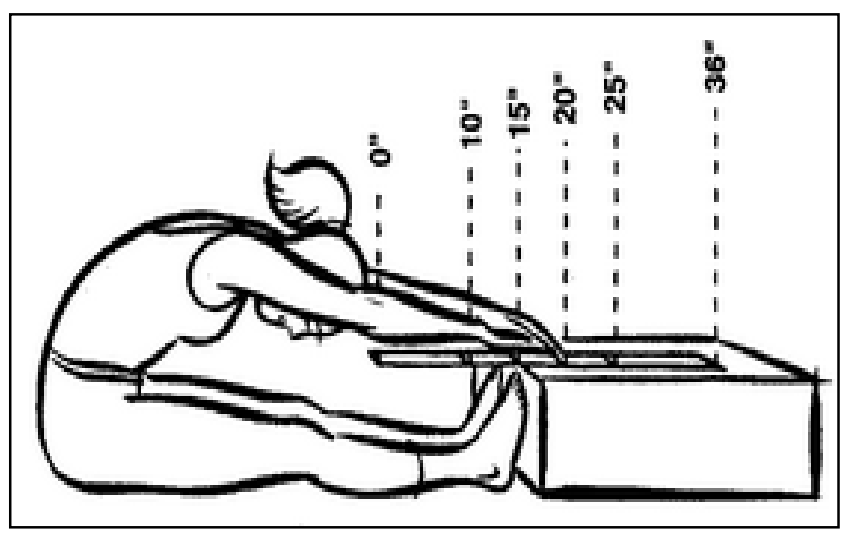

Fig. 9. Sit and reach

This data analysis is aimed at identifying the effects of rhythmic gymnastics on early childhood. This study used data analysis (SPSS). This is table for athletes in Yogyakarta,Indonesia:

TABLE I. THE AGE TABLE OF SPECIAL REGIAN OF YOGYAKARTA IN INDONESIA

\begin{tabular}{|c|c|c|}
\hline Districts/City & $\begin{array}{c}\text { The Athlete } \\
\text { Number }\end{array}$ & The Athlete Age \\
\hline \multirow[t]{10}{*}{ Yogyakarta City } & 10 & 13 \\
\hline & & 11 \\
\hline & & 10 \\
\hline & & 10 \\
\hline & & 8 \\
\hline & & 9 \\
\hline & & 9 \\
\hline & & 8 \\
\hline & & 10 \\
\hline & & 10 \\
\hline \multirow[t]{7}{*}{ Bantul District } & 7 & 8 \\
\hline & & 9 \\
\hline & & 8 \\
\hline & & 10 \\
\hline & & 8 \\
\hline & & 10 \\
\hline & & 11 \\
\hline \multirow[t]{5}{*}{ Sleman District } & 5 & 8 \\
\hline & & 10 \\
\hline & & 7 \\
\hline & & 9 \\
\hline & & 7 \\
\hline \multirow[t]{4}{*}{ Kulon Progo District } & 4 & 16 \\
\hline & & 13 \\
\hline & & 13 \\
\hline & & 12 \\
\hline \multirow[t]{4}{*}{$\begin{array}{l}\text { Gunung Kidul } \\
\text { District } \\
\end{array}$} & 4 & 7 \\
\hline & & 9 \\
\hline & & 8 \\
\hline & & 7 \\
\hline
\end{tabular}




\section{RESULT AND DISCUSSION}

Special Region of Yogyakarta Indonesia is located in the south part of Java Island surrounded by the Central Java in Indonesia and the Indian Ocean. From the study above, we were able to deduce the different types of body movements from the early stages to the later stages. The location of the districts in the Special Region of Yogyakarta in Indonesia are very unique because there consist mainly of highlands and lowlands.

The results of the preliminary study conducted by the researcher from the $1^{\text {st }}$ of March to $31^{\text {st }}$ of May 2018 is described below:

\section{Age}

The athletes in the Special Region of Yogyakarta are between the ages of 7-16 years. the SPSS calculations on Standard Deviation was calculated to be 2,2117762145.

\section{School}

From table 1 it could be seen that students in the Elementary School between the ages of 7-12 years old dominated the Rhythmic Gymnastics and they started from childhood.

The trainers in the Special Region of Yogyakarta in Indonesia had good Human Resources. The trainers made sure the athletes were are at ease when practicing and they were kept from harsh environmental factors. The relationship between the trainers and the athletes' parents makes it easier for the athletes' daily routines to be supervised. It is essential to keep the athletes comfortable in order to achieve maximum results.

\section{CONCLUSION}

Rhythmic gymnastics in Special Region of Yogyakarta in Indonesia has good potentials because of the qualified Human Resources. This gymnastics is only participated by females who started from their early childhood. Rhythmic gymnastics deals with flexibility and bio motor components (such as strength, durability, agility, speed, and power) that were taught in early childhood. The body posture should be slim, small, longer limb than the body in other body movements. Therefore, it was concluded that the athletes that participated in rhythmic gymnastics since their early childhood were very flexible and ended up achieving a lot.

\section{REFERENCES}

[1] M. Fortios, P. Miltiadis, A. Eirini, S. Andromahi, "Dynamic Balance In Girls Practicing Recreational Rhythmic Gymnastics and Greek Traditional Dances", Science of Gymnastics Journal, 2012, vol. 5, no. 1, pp. $61-70$

[2] T. O. Bompa, G. G. Haff, Periodization Theory and Methodology of Training. European, 2009.

[3] L. Svobodová, A. Skotáková, P. Hedbávný, P. Vaculíková, M. Sebera, "Use of the dance pad for the development of rhythmic abilities", Science of Gymnastics Journal, 2016, vol. 8, no. 3, pp. 283-293.

[4] E. Kosmidau, E. Giannitspoulou, M. Proios "Perceived locus of control in rhythmic gymnastics by coaches and judges", Sport Science Review, 2015, vol. XXIV, no. 1-2, pp. 89-102.

[5] Z. Wang "Proprioception influence on rhythmic gymnastics sport skill formation based on physiology theory", Journal of Chemical and Pharmaceutical Research, 2016, vol. 1, pp. 57-61.

[6] L. Ávila-Carvalho, P. Klentrou, M. d. L. Palomero, E. Lebre, "Body composition profile of elite group rhythmic gymnastics", Science of Gymnastics Journal, 2014, vol. 4, no. 1, pp. 21-32.

[7] D. L. Gallahue, J. C. Ozmun, "Understanding Motor Development (Infants, Children, Adolescents, and Adults)". New York: McGrawHill, 2006.

[8] FIG, "FIG Apparatus Norm", Eropa, 2018.

[9] L. A. Carvalho, P. Klentrou, E. Lebre, "Handling, throws, catches and collaborations in elite group rhythmic gymnastics", Science of Gymnastics Journal, 2012, vol. 4, no. 3, pp. 37-47.

[10] UNICEF, "Protecting Chilfren From Violence In Sport". Italy: ABC Tipografikasri, 2010

[11] UNICEF, "Early Learning and Development Standarsfor Children From 0-6 Years". Italy, 2009.

[12] YMCA, "Facilitating the Health Development of Children 7-11 Years". Greater Toronto, Kanada, 1995. 